\title{
Evaluation of Pressure Distribution in Buried Pipes with Liquid in the Explosion
}

\begin{abstract}
M. Parviz ${ }^{1}$, B. Aminnejad ${ }^{2}$, A.R. Fiouz ${ }^{3}$
In this Paper, a parametric study on pipes buried in soil was performed illustrating the results of blast loading. Effects of various parameters such as the physical properties of water, oil, gas, air, soil, pipes, and TNT have been investigated. The arbitrary Lagrangian-Eulerian (ALE) method was employed using LS-DYNA software. The maximum pressure in a buried pipe explosive was observed at an angle of about $0^{\circ}$ to $45^{\circ}$ and the minimum pressure occurred at an angle of about $45^{\circ}$ to $90^{\circ}$. Therefore, all figures in this study illustrate that fluid pressure levels in buried pipes can help in their stabilization. In generally, by increasing the 1.23 times of liquid density under the explosion, the pressure levels in the soil decreased by 1.3 percent. The gas pressure has been increasing more than oil and water pipes 39.73 and 40.52 percent, respectively.
\end{abstract}

Keywords: Buried pipe, ALE, Blast, Pressure, Ls-Dyna

\footnotetext{
${ }^{1}$ Ph.D. Graduates, Structural Engineering, Department of Civil Engineering, Roudehen Branch, Islamic Azad University, Iran, (Corresponding author, Email: Mohsen_Parviz1987@yahoo.com)

${ }^{2}$ Assistant Professor, Department of Civil Engineering, Roudehen Branch, Islamic Azad University, Iran, (E-mail: Aminnejad@riau.ac.ir)

${ }^{3}$ Assistant Professor, Department of Engineering, Persian Gulf University, Bushehr, Iran, (E-mail:Alireza_Fiouz@yahoo.com)
} 


\section{INTRODUCTION}

Anirban studied the effects of surface blasts on dry and cohesionless soil . He applied the ALE method and concluded that the metal behaviors in soil in large deformationa have an important parameter influence on analysis [1]. Liquid explosion tests are performed in large tunnels due to limited testing conditions, funding, and other various reasons. Therefore, many researchers carried out tests in vessels and pipelines on a small scale in laboratory environment [2]. Blanchard et al investigated explosions in an $18 \mathrm{~m}$ long ${ }^{1} \mathrm{DN} 150$ closed pipe with a 90 degree bend. It was demonstrated that the bend in a long tunnel could much improve flame speeds and overpressures, as well as shorten the run-up distance to ${ }^{2}$ DDT [3]. The effect of variations in the distribution of liquid on explosion propagation characteristics was also investigated in experimental channels [4]. Various countries are actively exploring oil tank and oil and gas pipeline safety technology since the last century by producing two types of explosion suppression materials or products such as metal [5]. Metal explosion suppression material is widely utilized at present and it uses metal or organic polymer material as the substrate [6].It is also made into mesh or other shapes after adding functional additives. If filled or installed in oil storage devices, ground vehicles or armored equipment, aircraft or ship tank, it quickly transfers heat and builds up flame propagation suppression in order to prevent explosions and other accidents [7]. Zimerman concluded that this method is unsuitable for unsymmetric structures lying in the lowest depths [8].

\section{SHOCK PRESSURE AND IMPULSE}

After the shock wave has propagated through the air some radial distance from the center of the explosion, the air located immediately behind the shock front is highly compressed relative to ambient conditions, and behind this compressed air, at a distance known as the positive wavelength $\mathrm{L}_{\mathrm{w}}{ }^{+}$, the air is rarefied relative to ambient conditions. The resulting pressure-time pulse, illustrated by the solid curve in Fig. 1, is produced by the shock wave propagating at supersonic speeds by a fixed point relative to the center of the explosion. the time of arrival of the shock front after detonation, a near instantaneous increase in ambient pressure (i.e., an overpressure) occurs due to the highly compressed air of the shock front; this pressure is called the peak incident (or side-on) pressure $\mathrm{P}_{\text {so. }}$.

\footnotetext{
${ }^{1}$ Diametre Nominal

${ }^{2}$ Deflagration to Detonation Transfer
} 


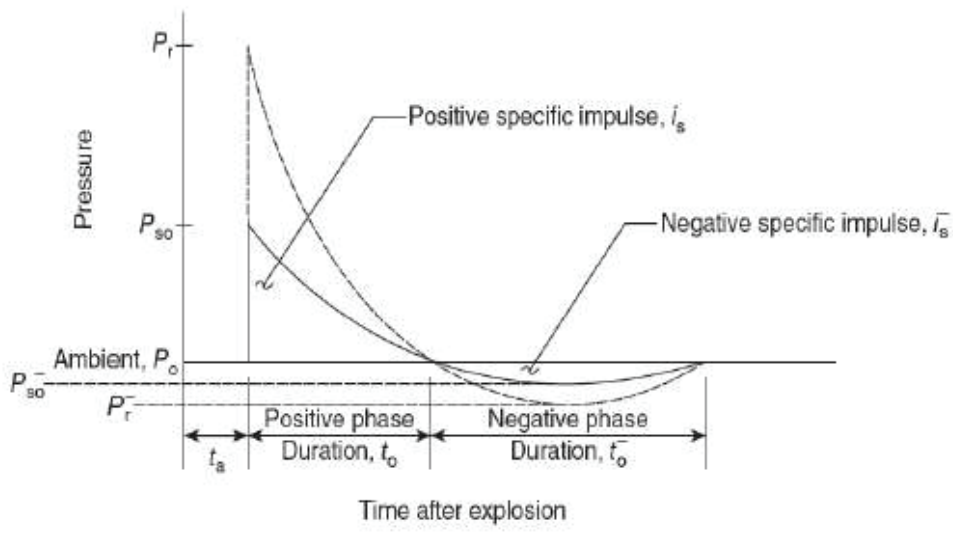

Fig. 1. Incident and reflected blast pressure pulses [9].

The positive pressure has been decreased during the time period $t_{0}$ and in the following the pressure decreases until below the ambient pressure surface. Negative pressure occurs during the time period $\mathrm{t}_{0}{ }^{-}$. Negative pressure is defined by changing the path of air particles flow at a distance with $\mathrm{L}_{\mathrm{w}}{ }^{-}$ length as suction pressure. The maximum negative pressure with $\mathrm{P}_{\mathrm{so}}{ }^{-}$can be observed in the figure. The positive phase wavelength also increases after the expansion of the pressure wave, which is due to the effects of dispersion. Generally, the positive peak pressure near the explosion can be higher than atmospheric pressure, which this event occurs in about one millisecond. The surface below the pressure diagram has been defined with $i_{s}$ and $i_{s}{ }^{-}$respectively, in terms of the positive and negative phase time, that can be observed in the figure.

\section{NUMERiCAl Simulation}

The study pipeline had the internal and external diameters of 0.36 and $0.4 \mathrm{~m}$ at its circular crosssection, respectively. For the load simulation, the equivalent pressure-time histories of explosiveloaded pipelines have been utilized in most of the previous studies. Great changes are usually exhibited in the pressure-time histories generated by high explosives even with equal charges. Clearly, structural responses can be strongly predicted by the generability of precise load functions. The explicit explosive modeling in this paper was done by simulating a high explosive detonation of LS-DYNA material specifically designed for this purpose. A simulation of complex real-world 
problems is possible via LS-DYNA as a finite element program for general purposes including bioengineering, manufacturing, construction, and the automobile, military, and aerospace industries. LS-DYNA is fully QA'd by LSTC. Its code is of a highly nonlinear origin to be applied in finite element transient dynamic analysis through an explicit time integration. The explosion was assumed to occur at the most unsuitable points, like at the air and soil interface above the pipeline. A quarter symmetrical model of $0.6 \mathrm{~m} \times 1.8 \mathrm{~m} \times 2 \mathrm{~m}$ was employed for saving the time of computation in the finite element model (Fig. 2). For an explicit 3D analysis, the 8-node elements of SOLID 164 were adopted. In this article, an arbitrary Lagrangian-Eulerian (ALE) algorithm was employed to prevent element distortion leading to large deformations in nonlinear structural analyses. Using ALE multimaterial meshes, modeling of the ${ }^{1} \mathrm{TNT}$ charge as well as of air, soil, and liquid in the pipelines was done. Thus, the pipelines were modelled with Lagrangian meshes, while setting the uniform mesh size at $5 \mathrm{~cm}$ and controlling the minimal time step with the smallest element size through the explicit integral method. To apply contact between the pipe and liquid, a software manual known as DATABASE_FSI (*CONSTRAINED_LAGRANGE_IN_SOLID), was used to examine the interaction of liquid and pipe. Moreover, the nodes must be transitionally displaced to the symmetrical planes. The other two lateral surfaces and the bottom surface were used with the nonreflecting boundary conditions, while the upper surface was associated with the free boundary condition. Here, the finite element model included the 5 materials of air, liquid, soil, pipeline, and TNT charge. One way to control the accuracy of the finite element is through energy balance. The energy dissipation is calculated and applied in energy balance. For this reason, in this paper the energy balance has been used. The depth of the pipe buried in the soil into explosive material is 1.2 meter [10].

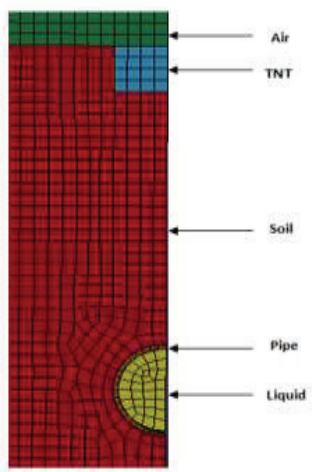

Fig. 2. Finite element model

\footnotetext{
${ }^{1}$ Tri Nitro Toluene
} 


\subsection{EXPLOSIVE MODEL}

In this article, the Jones-Wilkins-Lee (JWL) Equation of State (EOS) and a high explosive material model were utilized to model the TNT charge. The pressure was defined by JWL equation of state as follows [10]:

$$
\mathrm{P}=\mathrm{A}\left[1-\frac{\omega}{R_{1} V}\right] e^{-R_{1} V}+B\left[1-\frac{\omega}{R_{2} V}\right] e^{-R_{2} V}+\frac{\omega E}{V}
$$

Where $\mathrm{P}$ is the pressure, , A, B, $\mathrm{R}_{1}, \mathrm{R}_{2}$, and $\omega$ are the equation coefficients, $\mathrm{V}$ is initial relative volumes and $\mathrm{E}$ indicates the chemical explosive energy. Table 1 presents the parameters utilized in TNT charge model [10]:

Table 1. TNT charge parameters

\begin{tabular}{|c|c|c|c|c|c|c|c|c|c|}
\hline$\rho\left(\mathrm{kg} / \mathrm{m}^{3}\right)$ & $\mathrm{V}_{\mathrm{D}}(\mathrm{m} / \mathrm{s})$ & $\mathrm{P}_{\mathrm{CJ}}(\mathrm{Gpa})$ & $\mathrm{A}(\mathrm{Gpa})$ & $\mathrm{B}(\mathrm{Gpa})$ & $\mathrm{R}_{1}$ & $\mathrm{R}_{2}$ & $\omega$ & $\mathrm{V}$ & $\mathrm{E}(\mathrm{J} / \mathrm{kg})$ \\
\hline 1630 & 6930 & 21 & 374 & 3.23 & 4.15 & 0.95 & 0.38 & 1 & $6.00 \mathrm{E}+09$ \\
\hline
\end{tabular}

\subsection{AIR MODEL}

The air material model was commonly simulated by null material with a linear EOS, which defined the pressure by the following equation [10]:

$$
P=C_{0}+C_{1} \mu+C_{2} \mu^{2}+C_{3} \mu^{3}+\left(C_{4}+C_{5} \mu+C_{6} \mu^{2}\right) E_{0}
$$

where: $\mathrm{P}$ is stands for the pressure, $\mu$ - is a function of $\rho$ and $\rho_{0}$ as the reference density, $\mathrm{C}_{0}$ and $\mathrm{C}_{6}$ indicate constant coefficients, and $E_{0}$ is the initial internal energy of the reference specific volume per unit. The parameters used in the air model are given in Table 2 [10]:

Table 2. Air Parameters

\begin{tabular}{|c|c|c|c|c|c|c|c|c|}
\hline$\rho\left(\mathrm{kg} / \mathrm{m}^{3}\right)$ & $\mathrm{C}_{0}$ & $\mathrm{C} 1$ & $\mathrm{C} 2$ & $\mathrm{C} 3$ & $\mathrm{C} 4$ & $\mathrm{C} 5$ & $\rho_{0}\left(\mathrm{~kg} / \mathrm{m}^{3}\right)$ & $\mathrm{E}_{0}(\mathrm{~J} / \mathrm{kg})$ \\
\hline 1.29 & 0 & 0 & 0 & 0 & 0.4 & 0.4 & 1 & $2.5 \times 10^{5}$ \\
\hline
\end{tabular}




\subsection{Steel Pipe Model}

In this study, several kinds of steel pipe and yield stress were investigated. The steel pipe material model utilized in this research is referred to as the "Plastic Kinematic Model". The software selection is X80 and pipe modeling features are summarized in Table 3:

Table 3. Parameters of the X80 grade pipe material

\begin{tabular}{|c|c|c|c|c|}
\hline$\rho\left(\mathrm{kg} / \mathrm{m}^{3}\right)$ & $\mathrm{E}(\mathrm{Pa})$ & $v$ & $\delta \mathrm{y}(\mathrm{Pa})$ & $\operatorname{Etan}(\mathrm{Pa})$ \\
\hline 7850 & $2.10 \mathrm{E}+11$ & 0.3 & $6.57 \mathrm{E}+08$ & $1.35 \mathrm{E}+10$ \\
\hline
\end{tabular}

Where parameter E is the modulus of elasticity, $v$ Poisson's ratio, $\rho$ is density , $\delta$ y is yield stress and the parameter $\mathrm{E}_{\mathrm{tan}}$ is the tangent modulus. The steel pipe behaviour model shown in Fig. 3.

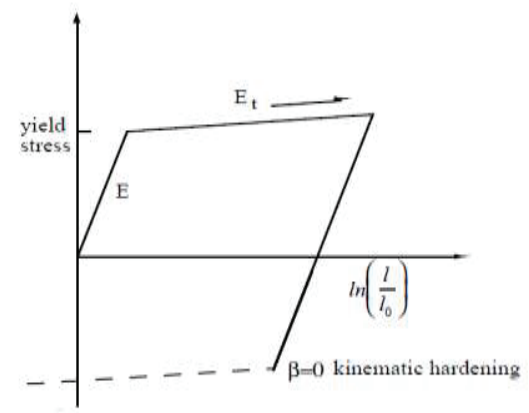

Fig. 3. Steel pipe behavior model [11]

$$
\sigma=E_{S} \varepsilon
$$

$$
\sigma=\sigma_{\mathrm{y}}+\mathrm{E}_{\mathrm{tan}}\left(\varepsilon-\varepsilon_{e}\right) \quad \varepsilon>\varepsilon_{e}
$$




\subsection{WATER MODEL}

To define theoretical pressure the Mie-Grüneisen EOS was commonly applied to the first water model using a null material model:

$$
P=\frac{\rho_{0} C^{2} \mu\left(1+\left(1-\frac{\gamma_{0}}{2}\right) \mu-a \frac{\mu^{2}}{2}\right)}{\left(1-\left(S_{1}-1\right) \mu-S_{2} \frac{\mu^{2}}{(1+\mu)}-S_{3} \frac{\mu^{3}}{\left(1+\mu^{2}\right)^{2}}\right)}+\left(\gamma_{0}+a \mu\right) \mathrm{E}
$$

Where $P$ indicates the pressure, $\mu$ is a function of $\rho$ and $\rho_{0}$ is the reference density, $S_{1}$ to $S_{3}, \gamma_{0}$ and $\alpha$ stand for the constant coefficients, $\mathrm{E}$ is the internal energy per volume unit, $\mathrm{C}$ is the velocity of sound propagation through water. The parameters applied in the water model are exhibited in Table 4 [10]:

Table 4. Water Parameters

\begin{tabular}{|c|c|c|c|c|c|}
\hline$\rho\left(\mathrm{kg} / \mathrm{m}^{3}\right)$ & $\mathrm{C}(\mathrm{m} / \mathrm{s})$ & $\mathrm{S}_{1}$ & $\mathrm{~S}_{2}$ & $\mathrm{~S}_{3}$ & $\gamma_{0}$ \\
\hline 1025 & $1.48 \mathrm{E}+03$ & 142 & 0.33 & 0.7 & 0.50 \\
\hline
\end{tabular}

\subsection{OIL MOdeL}

The oil was commonly modeled by a null material model with a Grüneisen equation of state (EOS), where $\rho_{0}$ and $\rho$ are the density and $S_{1}$ to $S_{3}, \gamma_{0}$ and $\alpha$ are the constant coefficients of the equation. $C$ is the velocity of sound propagation in the oil. Table 5 presents the parameters utilized in the oil model:

Table 5. Oil Parameters

\begin{tabular}{|c|c|c|c|c|c|}
\hline$\rho\left(\mathrm{kg} / \mathrm{m}^{3}\right)$ & $\mathrm{C}(\mathrm{m} / \mathrm{s})$ & $\mathrm{S}_{1}$ & $\mathrm{~S}_{2}$ & $\mathrm{~S}_{3}$ & $\gamma_{0}$ \\
\hline 800 & 1280.61 & 0 & 0 & 0 & 0.3 \\
\hline
\end{tabular}




\subsection{GAS MODEL}

The gas was commonly simulated by a null material model with a linear EOS, where $\rho$ is the density and $\mathrm{C}_{0}$ to $\mathrm{C}_{3}$ are the constant coefficient of the equation. Table 6 presents the parameters utilized in the gas model:

Table 6. Gas Parameters

\begin{tabular}{|c|c|c|c|c|c|}
\hline$\rho\left(\mathrm{kg} / \mathrm{m}^{3}\right)$ & $\mathrm{C}_{0}$ & $\mathrm{C} 1$ & $\mathrm{C} 2$ & $\mathrm{C} 3$ & $\mathrm{E}_{0}(\mathrm{~J} / \mathrm{kg})$ \\
\hline 0.65 & 0 & 0 & 0 & 0 & $2.5 \times 10^{5}$ \\
\hline
\end{tabular}

\subsection{SOIL MODEL}

Modeling of the soils was done using the simple and useful "soil and foam" model raised by Krieg in 1972, which could be operated as a fluid in some way. The model's main parameters in soil type I include a density equal to $1225 \mathrm{~kg} / \mathrm{m}^{3}$, a bulk modulus of $5.51 \mathrm{Mpa}$, a shear modulus of $1.72 \mathrm{MPa}$, and the yield function constants of $\mathrm{a}_{0}=0, \mathrm{a}_{1}=0$, and $\mathrm{a}_{2}=0.87$. Parameters of soil type II include a density equal to $1800 \mathrm{~kg} / \mathrm{m}^{3}$, a shear modulus of $11 \mathrm{Mpa}$, a bulk modulus of $190 \mathrm{MPa}$, and the yield function constants of $\mathrm{a}_{0}=0.33 \mathrm{Mpa}^{2}, \mathrm{a}_{1}=0.7 \mathrm{Mpa}$ and $\mathrm{a}_{2}=0.33$ [10]. The soil behaviour model is shown in Fig. 4.

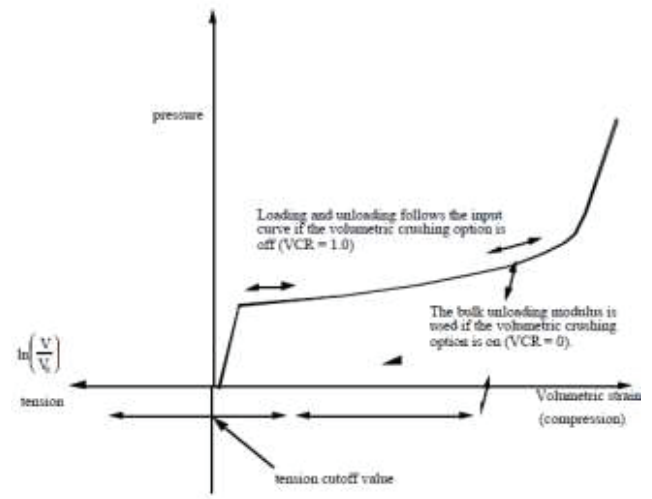

Fig. 4. Pressure versus volumetric strain curve for soil and foam model [11] 


\section{The Performance Of BURIEd Steel PiPe IN SOIL UNDER ELEMENTAL EXPLOSION}

The 4 elements selected with respect to the pipeline cross-section are represented in Fig. 5. They are at angles of $0^{\circ}, 22.5^{\circ}, 45^{\circ}$, and $90^{\circ}$ around the cross-section, respectively. Fig. 6 shows compression of the upper pipeline under the explosive load of $6.5 \mathrm{~kg}$ From among all the 4 peak values, the maximum pressure of $580.9 \mathrm{MPa}$ occurred at element H17968, while H17788, H17728, and H17668 represented the declining pressures of $356.1 \mathrm{MPa}, 129.3 \mathrm{MPa}$, and $82.3 \mathrm{MPa}$, respectively.Therefore, the maximum pressure for buried pipe explosive was seen when the angle was between $0^{\circ}$ to $45^{\circ}$ and the minimum pressure occurred when the angle was about $45^{\circ}$ to $90^{\circ}$. Therefore, the maximum pressure of the buried pipe is very sensitive to the shear modulus, bulk modulus, and density of the soil. Therefore, the top of the pipeline was the most vulnerable, so this area of the pipeline ranging from 0 to $45^{\circ}$ was the vulnerable area.

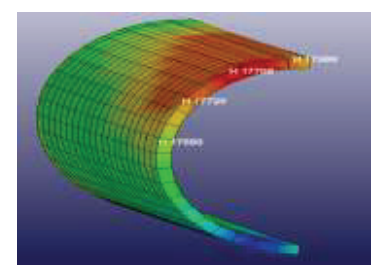

Fig. 5. Pressure contours on four elements of the pipeline with $6.5 \mathrm{~kg}$ of TNT

Fig. 6 illustrates the pressure value of pipe elements (H17968, H17788, H17728, and H17668) for $10 \mathrm{~ms}$, and a comparison of the numerical simulation with the current study data to the pipe buried under the explosion is illustrated. The time of the peak pressure is very important in the explosion, thus validation is performed at that specific time in this paper. The peak pressure of propagation of the shock wave between the numerical simulation and the current numerical, are 580.9 MPa and 535.3 MPa, respectively. The error between the numerical simulation and current study data is $7.85 \%$, thus, the numerical simulation results were quite in agreement with the current study values. The numerical simulation results similar to the current study values. Also, the results show good agreement with current study data [10]. Fig.6 illustrates the pressure value of the pipe elements which slight increases at first, then increases to a peak, and then finally decreases. This occurs because the explosive loading direction opposite to the pressure of fluid in a buried pipe, where 
there is reduced pressure. The maximum pressure peaks of the four elements appear almost at the same time.

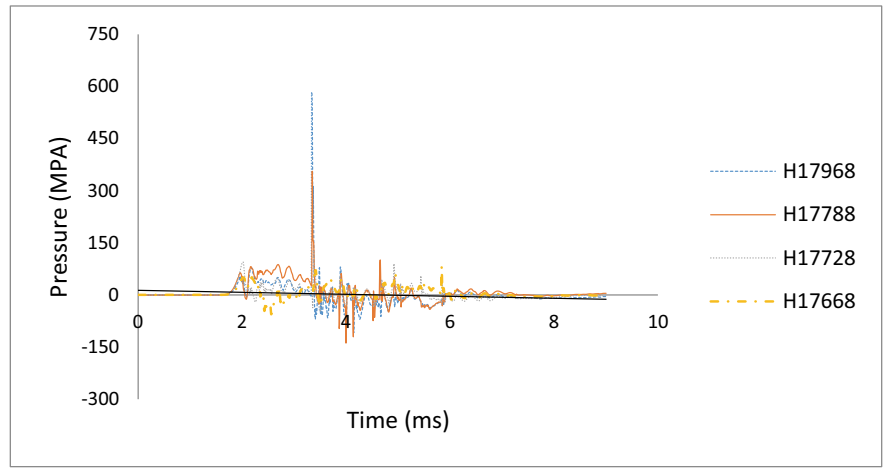

Fig. 6. The pressure-time curve of four different elements of water in buried pipe for $6.5 \mathrm{~kg}$ under explosion

Generally, after a pressure peak, when the pressure peak falls back, the pressure curves of a pipe shake slightly and then fall to a stationary value, so the pressure of the fluid in the buried pipe can help in stabilizing pipe pressure. Where pressure is positive in compression and negative in tension, the peak pressures of all elements are compressed. In general, the time of the peak pressure is very important in the explosion, and so validation is performed at the time of peak pressure of the explosion in this paper. As for the numerical simulation, the incident shock wave occurs at $3.33 \mathrm{~ms}$, with a peak pressure of 580.9 MPA. The maximum pressure peak in the current study is 535.3 MPA [10].

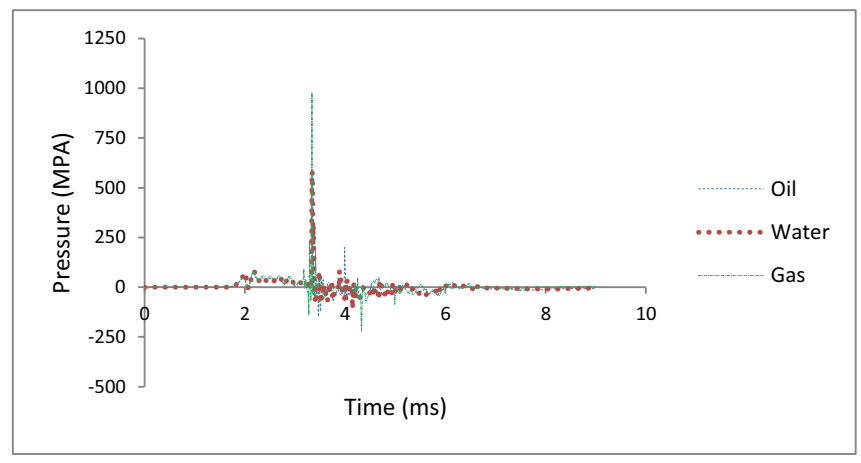

Fig. 7. Comparing the pressure-time curve of oil, water, and gas in buried pipe for $6.5 \mathrm{~kg}$ under explosion 
Fig. 7 shows the pressure-time curve of the buried pipe by decreasing the fluid density from 1025 $\mathrm{kg} / \mathrm{m}^{3}$ to $800 \mathrm{~kg} / \mathrm{m}^{3}$ and also the fluid density decreasing to $0.65 \mathrm{~kg} / \mathrm{m}^{3}$. Fig. 7 shows a comparison between oil, water, and gas. As it can be seen from Fig. 7, peak pressure occurs at about 3.33 milliseconds for all fluids. Also, as seen in Fig.7, the pipe has undergone increased pressure by reducing the fluid density in a way where the peak pressures for gas, oil, and water have become equal to $976.67,588.6$, and $580.91 \mathrm{MPa}$, respectively. This indicates that the higher the fluid density, the less pressure will be imposed on the pipe - and vice versa. This is confirmed by the results shown in Fig. 7.

\section{CONCLUSION}

In this paper the conclusions are as follows:

1. The figures show that the pressure values of pipe crown elements slightly increase first, then increase to a peak, and finally decrease. This is because the explosive loading direction is opposite to the pressure of fluid in the buried pipe, which leads to a decrease in pressure. The maximum pressure for buried pipe explosives was seen when the angle was between $0^{\circ}$ and $45^{\circ}$ and the minimum pressure occurred when the angle was between $45^{\circ}$ and $90^{\circ}$. Therefore, the maximum pressure of the buried pipe is very sensitive to the shear modulus, bulk modulus, and density of the soil.

2. Generally, after a pressure peak, when the pressure peak falls back, the pressure curves of a pipe shake slightly and then fall to a stationary value, so the pressure of the fluid in the buried pipe can help in stabilizing pipe pressure. Therefore, the top of the pipeline was the most vulnerable. When pressure is positive in compression and negative in tension, the peak pressures of all elements are compressed.

3. In generally, by increasing the 1.23 times of liquid density under the explosion, the pressure levels in the soil decreased by 1.3 percent. The gas pressure has been increasing more than oil and water pipes 39.73 and 40.52 percent, respectively, so the results show that the higher the fluid density, the less pressure will be imposed on the pipe. 


\section{REFERENCES}

1. De, A., "Numerical simulation of surface explosions over dry, cohesionless soil", Computers and Geotechnics 43: 72-79. 2012.

2. Thom C, Cronin D. Shock wave amplification by fabric materials. Shock Waves, 2009, 19: 39-48. doi: 10.1007/s00193-009-0186-x

3. Blanchard R, Arndt D, Gra" tz R, et al. Explosions in closed pipes containing baffles and 90 degree bends. J Loss Preven Process IND, 2010, 23: 253-259.doi: 10.1016/j.jlp.2009.09.004

4. Guo Ch, Lin B, Zhu Ch, et al. Effect of filling ratio of premixed methane/air explosion in an open-end pipe. International Journal of Spray and Combustion Dynamics, 2016, 1: 1-7.

5. Lou Ch, Ruihai W, Liang w. An Explosion Suppression Material and Its Manufacturing Method [P], 2002, CN: $101906561 \mathrm{~A}, 02-02$.

6. Youjie Zh, Gaojun A, Xudong w. Study on Explosion Suppression Technologies for Oil and Gas Pipeline Procedia Engineering, 2014, 84: 412-418.

7. RU C-Y, WANG D-X. The explosion-proof mechanism and application of HAN blocking explosionproof technology. China Science and Technology Information, 2006, 18:295-296.

8. Zimmerman, H., Cooper, G., Carney, J. and Ito, Y. Cratering and ground shock environment prediction of buried armor piercing bomb in dry Socorro plaster sand, Technical Report CRT-3295-010-01, California Research and Technology, Chattsworth Calif, 1990.

9. Baker W.E, Cox P, Westin P.S,Kulesz J.J,Strehlow R.A. Explosion hazard and evaluation. Elsevier, New York.

10. Yan $\mathrm{S}, \mathrm{Xu} \mathrm{Y}$, Chang H. Numerical simulation of dynamic response of buried pipeline by ground explosion. Journal of Earth and Space, ASCE, Pp. 1159-1166, 2012.

11. LS-DYNA keyword user's manual Vol. 1. Version 971, Livermore Software Technology Corporation (LSTC), California, USA, 2013.

\section{LIST OF FigURES AND TABLES:}

Fig. 1. Incident and reflected blast pressure pulses

Fig. 2. Finite element model

Fig. 3. Steel pipe behavior model

Fig. 4. Pressure versus volumetric strain curve for soil and foam model

Fig. 5. Pressure contours on four elements of the pipeline with $6.5 \mathrm{~kg}$ of TNT

Fig. 6. The pressure-time curve of four different elements of water in buried pipe for $6.5 \mathrm{~kg}$ under explosion

Fig. 7. Comparing the pressure-time curve of oil, water, and gas in buried pipe for $6.5 \mathrm{~kg}$ under explosion

Table. 1. TNT charge parameters

Table. 2. Air Parameters

Table. 3. Parameters of the X80 grade pipe material

Table. 4. Water Parameters

Table. 5. Oil Parameters

Table. 6. Gas Parameters

Received 09.02.2017

Revised 07.08.2019 